\title{
Partial and Contingent Recoil-Frame Covariance-Map Imaging
}

David Heathcote and Claire Vallance*

Department of Chemistry, University of Oxford, Chemistry Research Laboratory,

12 Mansfield Rd, Oxford OX1 3TA, UK

e-mail: claire.vallance@chem.ox.ac.uk

(i) $\mathrm{N}_{2} \mathrm{O}^{2+} \rightarrow \mathrm{N}^{+}+\mathrm{NO}^{+}$
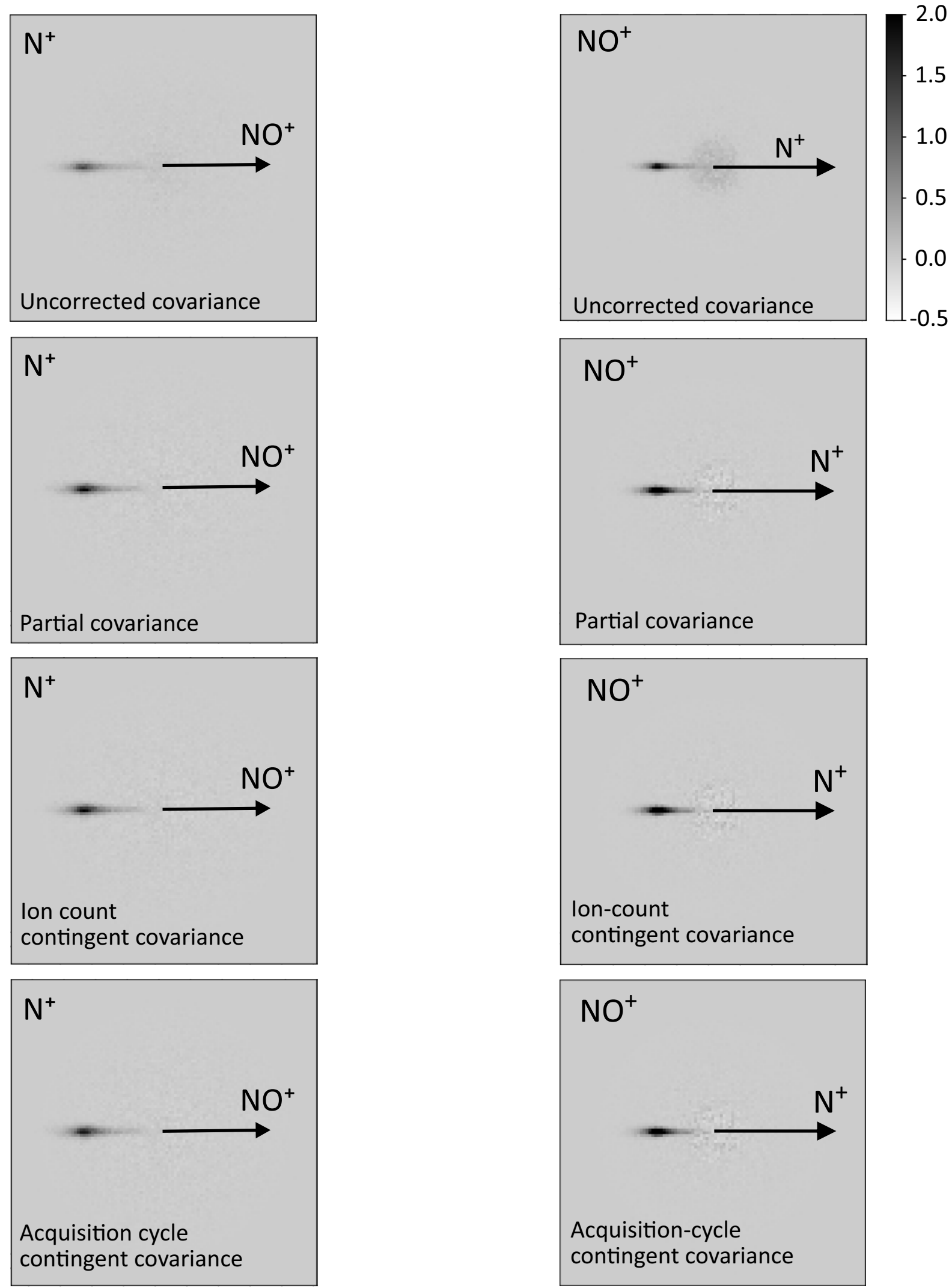

Figure S1: Recoil-frame covariance maps for the $\mathrm{N}^{+}+\mathrm{NO}^{+}$fragmentation channel of $\mathrm{N}_{2} \mathrm{O}^{2+}$, with $\mathrm{NO}^{+}$ as the reference ion in the left hand panel, and $\mathrm{N}^{+}$as the reference ion in the right hand panel. See main text for details of the four different covariance methods employed. 
(ii) $\mathrm{N}_{2} \mathrm{O}^{2+} \rightarrow \mathrm{N}_{2}^{+}+\mathrm{O}^{+}$
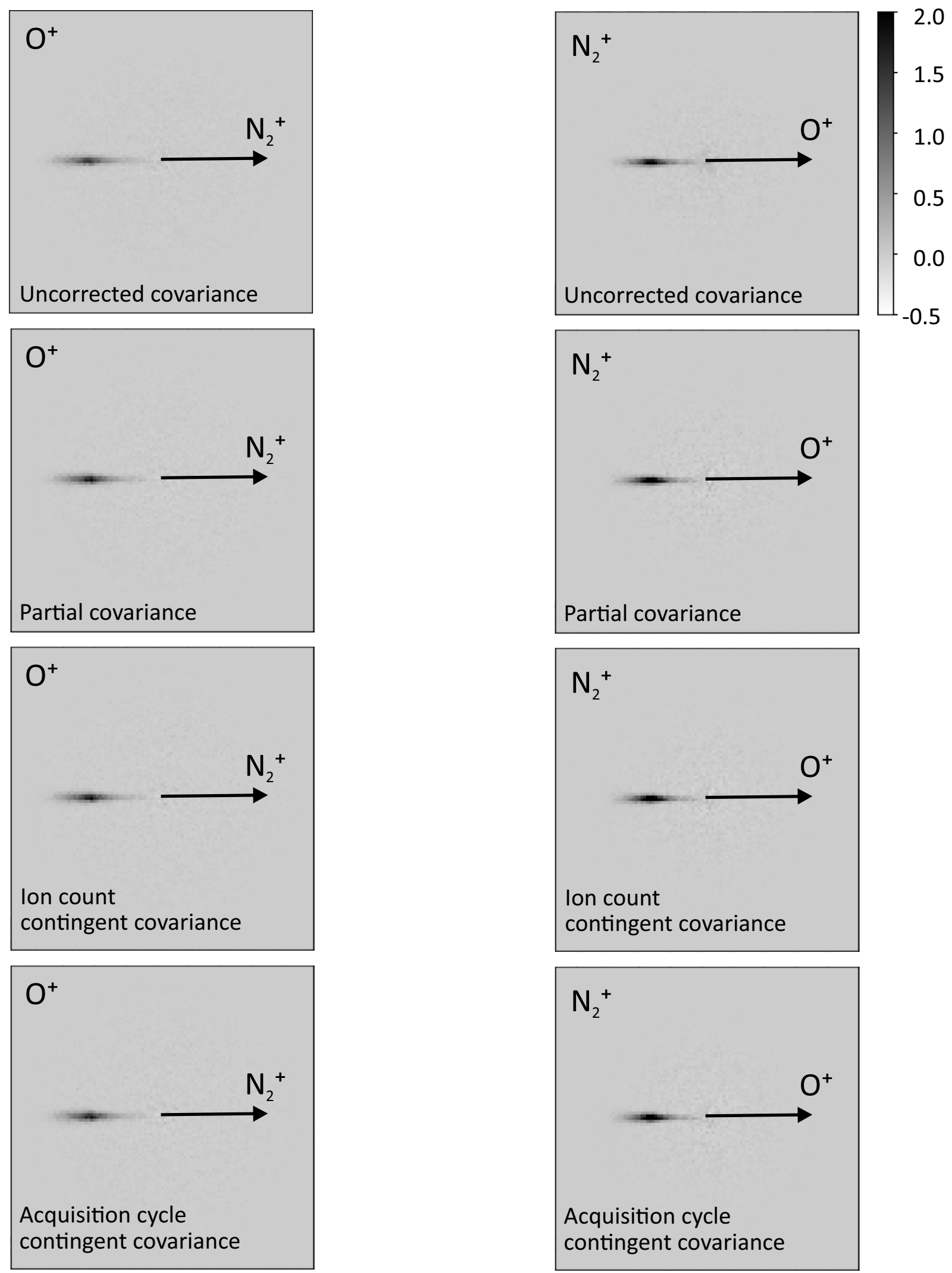

Figure S2: Recoil-frame covariance maps for the $\mathrm{N}_{2}^{+}+\mathrm{O}^{+}$fragmentation channel of $\mathrm{N}_{2} \mathrm{O}^{2+}$, with $\mathrm{N}_{2}^{+}$ as the reference ion in the left hand panel, and $\mathrm{O}^{+}$as the reference ion in the right hand panel. See main text for details of the four different covariance methods employed. 
(iii) $\mathrm{N}_{2} \mathrm{O}^{2+} \rightarrow \mathrm{N}+\mathrm{N}^{+}+\mathrm{O}^{+}$
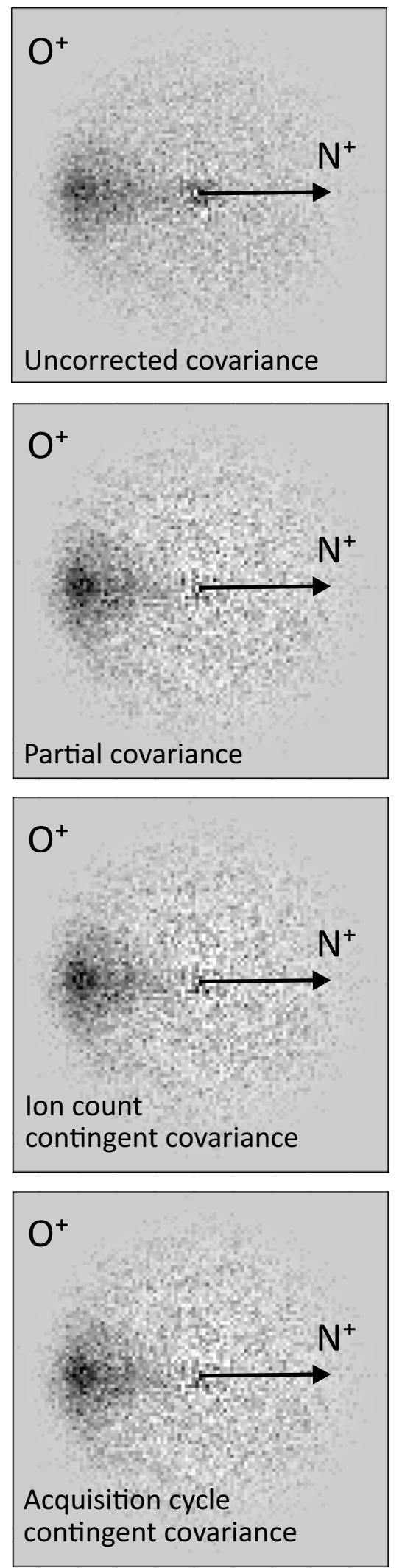
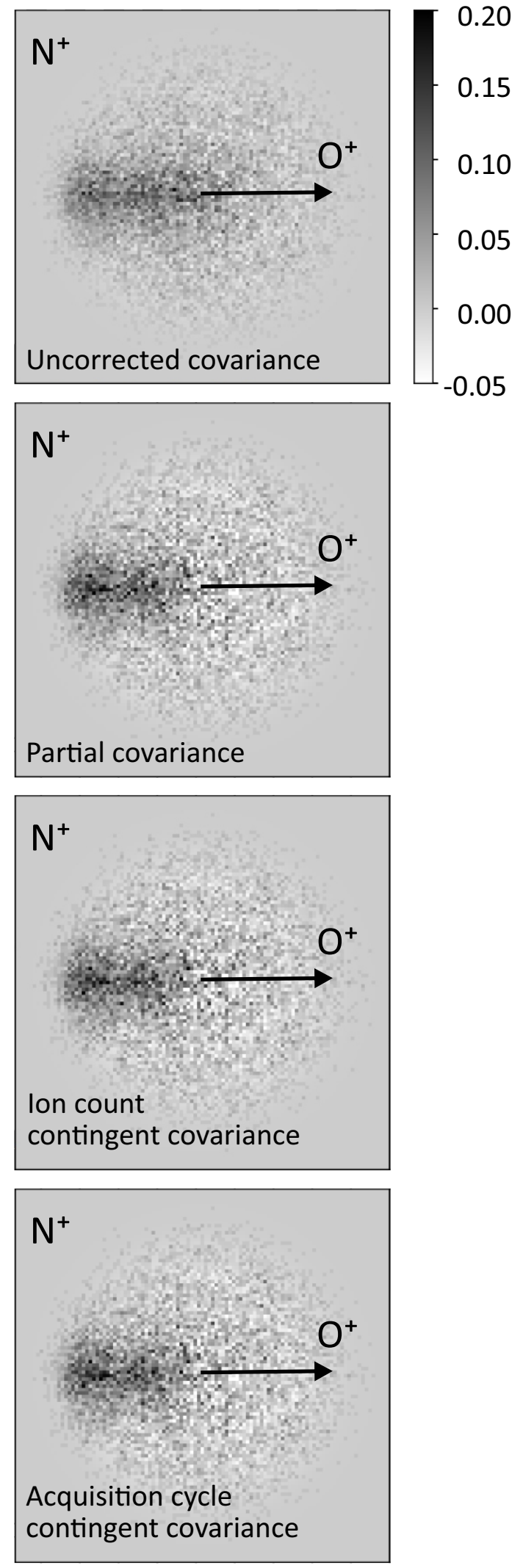

Figure S3: Recoil-frame covariance maps for the $\mathrm{N}+\mathrm{N}^{+}+\mathrm{O}^{+}$fragmentation channel of $\mathrm{N}_{2} \mathrm{O}^{2+}$, with $\mathrm{N}^{+}$ as the reference ion in the left hand panel, and $\mathrm{O}^{+}$as the reference ion in the right hand panel. See main text for details of the four different covariance methods employed. 
(iv) $\mathrm{N}_{2} \mathrm{O}^{2+} \rightarrow \mathrm{N}^{+}+\mathrm{N}^{+}+\mathrm{O}$
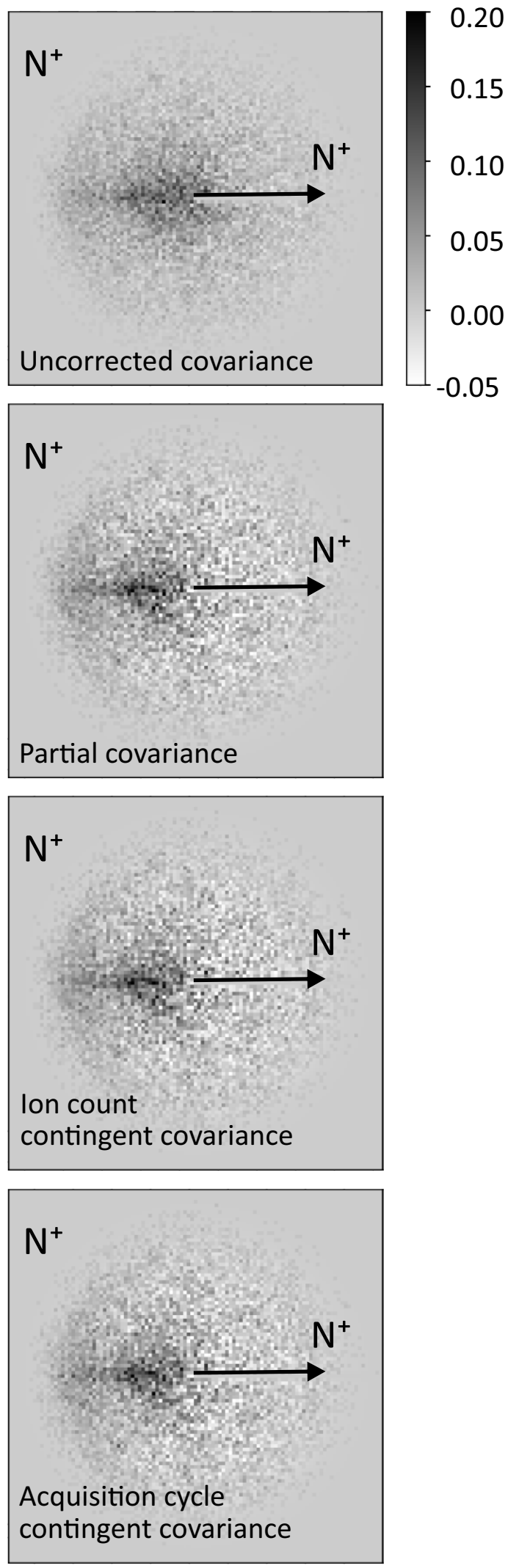

Figure S4: Recoil-frame covariance maps for the $\mathrm{N}^{+}+\mathrm{N}^{+}+\mathrm{O}$ fragmentation channel of $\mathrm{N}_{2} \mathrm{O}^{2+}$. See main text for details of the four different covariance methods employed. 